\title{
DIFFERENCES IN USING LMS OR SOCIAL NETWORKS IN EDUCATION
}

\section{Abstract}

In recent years, the use of the learning management system (LMS) in the educator's practical work is becoming more popular and has many advantages: it allows students to get knowledge faster and deeper, facilitates interaction between students and educators. In addition, the LMS use increases the students' number in distance education. Academic group in the social network Facebook is used both in the students' daily life, and is considered as an educational tool. The social network can easily be adapted as an additional learning management system due to the fact that virtual space become a part of our lives and it can be used efficiently to solve much problems "on the spot". However, the full impact of the academic group in Facebook on learning has not been studied, especially when compared with the use of other training management systems. According to the study results, the Facebook group members surpassed academically those who used Moodle. Moreover, Facebook users held a positive attitude towards learning and interaction, higher motivation to learn compared to Moodle users. This article provides an implementation analysis and possible limitations in the use of the training management system. The study results may be of great interest to educators who suggest taking Facebook as one of the training management systems.

Keywords: learning management systems, social networking technologies, higher education, distance education, online platform integration, education tools, communication tools.

Learning Management System (LMS) is a software for creating and managing sites for training (Li L., Pitts J. P., 2009). Each LMS has its own interface, however, most LMS have the same functions:

- Image. LMS allows you to download training resources (text documents, multimedia files and Internet resources). Resources can be organized according to learning needs, 
such as topics and training schedule.

- Interaction tools. LMS provide a means of communication: announcements, forums and messages for individual and group interactions.

- Tools for monitoring and evaluating the quality of management. Student participation in exams, group work, feedback and certification training activities.

The adoption of a learning system (LMS) has become common in higher education and has many advantages in both teaching and learning (McCarthy J., 2010). Accordingly, the developed training systems (LMS) provide an environment that allows you to actively study and facilitates the interaction between students and teachers (Wang Q., 2008). In addition, the use of learning system (LMS) increases the number of students of distance education.

However, the use of existing commercial and free Learning Management Systems (LMS) often poses limitations. The following are examples.

Commercial Learning Management Systems (LMS) are expensive, which is becoming a "burden" for institutions that host and support these systems. Teachers cannot create courses or discussion groups, as these functions are available to system administrators (Coats H.J.R., Baldwin G., 2005).

When learning system (LMS) are free, teachers must use the technical knowledge to fill the system. Resources in the Learning System (LMS) are not available to students after completing or completing the course, or when replacing the Learning System (LMS).

Internet social networking tools with built-in Web 2.0 concept became popular in everyday life (Ajjan H., Hartshorne R., 2008, Kop R., Fournier H., Mak J. S. F., 2001, DeSchryver M., Mishra P., Koehler M., Francis A., 2009).

People tend to develop social relationships with friends, classmates, colleagues, and family members using social networking technologies such as Facebook, Twitter, Tumblr, Instagram, and microblogging (Shih R., 2011). Easy access and social connections using social networking technologies facilitate distance learning.

According to Facebook (Facebook, "Investor Relations: Facebook Reports First Quarter 2014 Results), more than 1.28 billion active users shared files and communicated in groups using Facebook. In addition, Facebook is a free and popular resource where the content of training is available after the completion of the course, and teachers do not need special technical knowledge to install this LMS. Facebook is considered to be a training tool (Nunes M.B., McPherson M., 2003)., which promotes interaction, learning, 
motivation to learn and of classroom climate:

\section{Facebook: engagement and classroom climate}

Allows students to share, reflect and learn, increasing the effectiveness of student learning (McCarthy J., 2010). The academic group provided an environment in which they share their impressions, thoughts, resources, and comments, which contributes to the learning process. Lee and (Pitt Li L., Pitts J.P., 2009)., Hewitt and Forte (Hewitt, Forte A. Crossing boundaries: identity management and students/faculty relationships on the Facebook), Mather, Murphy and Symonds (Mazer J.P., Murphy R.E., Simonds C.J., 2007). noted that Facebook groups improve the relationship between students and teachers, and promote a positive attitude towards courses and teachers. Interactions in online discussions help learning and provide a supportive learning environment for student selfeducation.

\section{Facebook: learning and motivation}

Schroeder J. and Green Bowe T. (Schroeder J., Green Bowe T. (2009) reported that students in social groups in Facebook discussing complex topics and gave detailed answers and discussion in Facebook groups contribute to the development of critical thinking.

Facebook affects students because the usage rate is over $90 \%$ per year (Facebook, “Investor Relations: Facebook Reports First Quarter 2014 Results”). However, before Facebook was not widely used in higher education, Facebook academic groups can be used as learning systems (LMS), the impact of Facebook groups on learning compared to a learning system (LMS) like Moodle remains limited. Kop (Kop R., Fournier H., Mak J.S.F., 2011) described the use of the academic group on Facebook, which was created and supported by participants in massive open online courses for self-study, determining that some students chose the Moodle forum instead of Facebook because they could get more background information (Wang Q., Woo H.L., Quek C.L., Yang Y., Liu M., 2012). The Facebook group was used as an additional tool for some students.

The need to collect additional data on the differences in learning outcomes between Moodle and Facebook has become decisive in connection with the rapid growth of mobile technologies [19]. Mobile Facebook allows students to share learning resources: the effect of learning Facebook on mobile devices was not compared with the results of other types of LMS (Sanchez R.A., Cortijo V., Javed U., 2014). In some studies, the Facebook mobile group was compared with the Moodle training system (LMS) in terms of academic 
performance, attitude to learning, interaction, learning motivation, as well as learning efficiency and teacher readiness.

\section{Objective}

Three groups of masters took part in this study. The study was conducted on the course "IT programming".

\section{The purpose of the study}

To determine whether academic groups on Facebook can be used as LMS. For comparison, two types of LMS were used: Facebook and Moodle. It was decided to check whether the academic results and preferences of students using different LMS are different.

As an analysis of the results was carried out private interviews (random face-to-face), on the experience of students in the appropriate use of LMS in practical classes. The purpose of the interview is to determine students' attitudes to using LMS and recommendations for improving LMS.

Quantitative data are scores and LMS survey results. Qualitative data was collected from the interview. Next, the integration of the Facebook group into the lives of students was investigated. The difference in attitude to learning, to interaction and motivation of students using different LMS (Facebook and Moodle). Students' experience in using different LMS (Facebook and Moodle) in their learning.

\section{Materials and research methods}

The academic IT group Facebook was created on the basis of the social network Facebook: initially the group was open, and users had concerns about the security of personal data. The Facebook group was subsequently set up as private, and only for group members: training resources and discussions are available only to them.

The Web 2.0 tool, Quibblo, was used to conduct a practical quiz on the Facebook group. The teacher creates quizzes and places a link on the wall on Facebook, after completion, students receive a recommendation (suggestions, comments) and statistics on learning outcomes. The system provides a platform on which users download assignments, training resources, publish and respond to messages, participate in practical quizzes and discuss group news.

The popular and free LMS - Moodle, used at most universities, provides similar features, as well as downloading and downloading files. In this study, two Learning 
Management Systems (LMS) were randomly selected: the Facebook academic group and the Moodle group. Students could access the academic group Facebook and Moodle using the Facebook and Moodle Mobile applications, respectively, on tablet PCs; since this course was relatively new, all participants had limited experience using LMS (Roselli R.J., Howard L., Brophy S., 2006).

To evaluate the three key functions in LMS, the teacher uploaded the training resources, and the students completed the tasks in formats such as Word, PowerPoint, pdf, jpg-files and web addresses on the "Walls on Facebook", "Theme page" page "Moodle and Learning Materials" for students to read. All participants had to read the announcements in the group and answer weekly discussion questions, as well as the publications of other classmates to interact with the groups in Events in Facebook, forums and discussions in Moodle. Student participation in weekly discussions was appreciated.

The training was conducted for 8 weeks. Participants had to undergo a preliminary general survey before and after to determine the difference in learning outcomes and interaction.

The first factor is "Attitude towards learning using different types of LMS". The second factor is "Attitude towards interaction using different types of LMS". The third factor is "Technological Efficiency and Readiness to Use LMS". The fourth factor is "Learning motivation when using different types of LMS".

\section{Research results and discussion}

Differences in Academic Performance Among Learning Management Systems (LMS). The average academic group score on Facebook was significantly higher than the average Moodle group score. The questionnaire included four indicators: relevance to learning using various types of LMS; relation to interaction using various types of LMS; technological efficiency and readiness to use LMS; learning motivation when using different types of LMS.

Attitude towards learning and interaction when using different learning management systems. The number of students in the Facebook academic group was significantly higher than that of students in the Moodle group. Technological efficiency, motivation and willingness to use Learning Management Systems (LMS). The willingness to apply the Facebook academic group in further work was significantly higher than that of students in the Moodle group. Facebook Academic Group: Simple but disjoint discussions. The students felt that Facebook presented a simple environment in which they could upload 
and edit: "The interface of the Facebook academic group is clear to me, I can easily find the course materials, the wall and the discussion area. It's convenient for me to study using general publications on topics."

Using Facebook groups to interact with other people is common for students and is a convenient approach: "I use Facebook daily, and if a new message is published, it automatically appears on the Facebook group wall. I don't need to log in to another system or remember another website."

Students identified some flaws in using Facebook academic groups. Often it was reported a drawback when messages may not be within the scope of the discussion topic: "messages are not processed, it is difficult to find and read related messages, especially when there are too many messages."

Since Facebook was designed for social purposes, students can be distracted, read news, play and chat with other people instead of learning: "I felt like I spent a lot of time reading messages and watching videos and photos that weren't related to learning. There were too many things that distracted me from learning." The Facebook academic group was open at the start of the study. Further, privacy settings were used, some students expressed concern that their personal information might be available: "I don't feel that participating in the Facebook academic group is safe." Moodle: technical problems, possible participation in discussions.

Most students agreed: "I learned a lot from others, they shared their experience and resources." In addition, most students agreed that their interaction with others improved: "I interact with others quite a bit on the Facebook system and felt very comfortable in this learning environment. Joint training with others benefits me and motivates me to further develop myself! "In addition, students noted that downloading files was easy and participating in discussions was convenient:" I can easily download materials, share resources with others and discuss topics with other students ".

Some students spent a considerable amount of time getting to know the interface. Most agreed that Moodle provides a simple and convenient interface with which you can study and participate in discussions: "It took me a while to get used to Moodle, in general, it is easy to use."

However, some students complained that the interface is too simple and based on the text: "I do not like the interface. It looks too boring, so I would not want to use this system. " 
Finally, Moodle was used only for the academic community. Therefore, students used this system when they were required to complete assignments: "I used the system when I needed to prepare and pass an assignment. In the main time I did not check the system and did not use it"; "I don't use Moodle every day, only when necessary, I often miss participation in discussions."

However, individual users encountered technical problems. Some students noticed that not all Internet browsers support the full Moodle functionality: "I can't download files using the built-in Android browser - this is very inconvenient"; "The message font size is only 6 pins, and it's hard to read." The system automatically registers the user. But there is a limitation: if it is idle for a certain period of time, the student must register again in the system: "I am not happy when the system asks to enter the account again after I have already logged in, due to inactivity for a period of one minute".

\section{Conclusions}

An analysis of the use of Facebook (compared to other types of LMS) confirmed that Facebook academic groups are suitable for higher and distance education.

Members of the Facebook academic group showed a positive attitude towards learning, a higher level of interaction and motivation than in the Moodle groups. Members of the Facebook academic group noted that using Facebook provides a convenient environment in which they can share resources and discuss topics with others. Moreover, they used Facebook in everyday life and agreed that Facebook makes it easy to improve social connections and does not require an additional special system. All this contributes to a positive attitude towards learning and active interaction in the academic group Facebook than in the group Moodle.

The Facebook group has demonstrated a high level of technological effectiveness as an LMS in higher education, but with a number of some limitations. Below are the main findings of the study:

The social network and the academic group on Facebook have become part of students' lives and provide a simple, convenient, easy learning environment. However, the number of participants in the academic community of Facebook should be limited to guarantee a quality management process; teachers and students were worried about the lack of attention: participants spent too much time reading messages and watching videos that were not related to the course, so necessary and consistent regulation was required; confidentiality is one of the problems for users of the academic community on Facebook: 
many were worried that their personal information and course activities might be available to strangers; It focuses mainly on masters using Facebook for academic purposes.

Similar studies can be conducted to examine the impact of using the Facebook group on students at different levels and subject areas. Since Facebook is not intended for educational purposes, there are more powerful LMS, for example, Canvas (Canvas. Choosing an LMS comes down to 3 simple questions) which provide more management functions, such as evaluation app, privacy and security control, guarantee and automatic load management.

\section{References}

Ajjan H., Hartshorne R. (2008). Investigating faculty decisions to adopt web 2.0 technologies: theory and empirical tests. The Internet and Higher Education, vol. 11, № 2. - pp. 71-80.

Canvas. Choosing an LMS comes down to 3 simple questions. - URL: http://www.instructure.com/compare-higher-education (10.11.2019)

Coats H.J.R., Baldwin G. (2005). A critical examination of the effects of learning management systems on university teaching and learning. Tertiary Education and Management. - vol. 11, №1. - pp. 19-36.

DeSchryver M., Mishra P., Koehler M., Francis A. (2009). Moodle vs. Facebook: does using Facebook for discussions in an online course enhance perceived social presence and student interaction? Proceedings of society for information technology \& teacher education international conference. - pp.329-336.

Facebook, “Investor Relations: Facebook Reports First Quarter 2014 Results”. URL: http://investor.fb.com/releasedetail.cfm?ReleaselD=842071. (10.11.2019)

Gabarre S., Gabarre C., Din R., Shah P.M., Karim A.A. (2013). Using mobile Facebook as an LMS: Exploring impeding factors. GEMA Online Journal of Language Studies, vol. 13, № 3. - pp. 99-115.

Hewitt, Forte A. Crossing boundaries: identity management and students/faculty relationships on the Facebook. http://www.mendeley.com/research/crossing-boundariesidentity-managementand-studentfaculty-relationships-on-the-facebook-2/\#page-1. (10.11.2019). 
Kop R., Fournier H., Mak J. S. F. (2001). A pedagogy of abundance or a pedagogy to support human beings? Participant support on massive open online courses. The International Review of Research in Open and Distance Learning, vol. 12, № 7. - pp. 74- 93.

Kop R., Fournier H., Mak J.S.F. (2011). A pedagogy of abundance or a pedagogy to support human beings? Participant support on massive open online courses . The International Review of Research in Open and Distance Learning, vol. 12, №7. - pp.74- 93.

Li L., Pitts J. P. (2009). Does it really matter? Using virtual office hours to enhance student-faculty interaction. Journal of Information Systems Education, vol. 20, № 2.-pp. 175-185.

Li L., Pitts J.P. (2009). Does it really matter? Using virtual office hours to enhance student-faculty interaction. Journal of Information Systems Education, vol. 20, № 2. - pp. 175-185.

Mazer J.P., Murphy R.E., Simonds C.J. (2007). I'll see you on Facebook: the effects of computer mediated teacher self-disclosure on student motivation, affective learning and classroom climate. Communication Education, vol. 56, №1. - pp. $1-17$.

McCarthy J. (2010). Blended learning environments: using social networking sites to enhance the first-year experience. Australasian Journal of Educational Technology, vol. 26, № 6.- pp 729-740.

McCarthy J. (2010). Blended learning environments: using social networking sites to enhance the first-year experience. Australasian Journal of Educational Technology, vol. 26, № 6. - pp. 729-740.

Nunes M.B., McPherson M. (2003). Action research in continuing professional distance education. Journal of Computer Assisted Learning, vol. 19, № 4. - pp. 429-437.

Roselli R.J., Howard L., Brophy S. (2006). Integration of formative assessment into online engineering assignments. Computers in Education Journal, vol. 16, №. 4. - pp. 8-17.

Schroeder J., Green Bowe T. (2009). The chemistry of Facebook: using social networking to create an online community for the organic chemistry laboratory. 
Journal of Online Education. - vol. 5, № 4. - URL: http://www.comminit.com/node/321375 (10.11.2019).

Shih R. (2011). Can Web 2.0 technology assist college students in learning English writing? Integrating Facebook and peer assessment with blended learning. Australasian Journal of Educational Technology, vol. 27, № 5, - pp. 829-845.

Sanchez R.A., Cortijo V., Javed U. (2014). Students' perceptions of Facebook for academic purposes. Computers \& Education, vol. 70. - pp. 138-149.

Wang Q. (2008). A generic model for guiding the integration of ICT into teaching and learning. Innovations in Educational and Teaching International, vol. 45, № 4. pp. 411-419.

Wang Q., Woo H.L., Quek C.L., Yang Y., Liu M. (2012). Using the Facebook group as learning management system: an exploratory study. British Journal of Educational Technology, vol. 43, № 3. - pp. 428-438. 